\title{
Dramatic rise in VRE infections linked to abandoned control measures
}

\author{
n Cite as: CMAJ 2019 August 6;191:E876. doi: 10.1503/cmaj.109-5794
}

Posted on cmajnews.com on July 18, 2019.

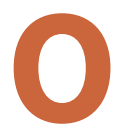

ntario has seen a rise in vancomycin-resistant enterococcus (VRE) infections over the past decade as many hospitals stopped programs to contain the antibioticresistant bug. Some are reinstating the programs, but the trend may prove difficult to reverse, says Dr. Jennie Johnstone, an infection prevention and control scientist based in Toronto. "It's very difficult to get the toothpaste back in the tube."

Johnstone led a Public Health Ontario study published in CMAJ Open that found rates of VRE bloodstream infections almost doubled between 2009 and 2015. Since then, VRE infection rates have doubled again, says Johnstone. Hospitals that stopped screening for VRE and isolating affected patients had an "exponential increase" in infection rates; those that continued these precautions had relatively flat rates. It's not possible to say whether stopping screening and isolation programs caused the rise in infection rates, Johnstone says. However, the link between the two was "very strong and persistent over time."

Many Canadian hospitals stopped screening and contact precautions for VRE over the past decade after studies called the practice into question, Johnstone says. National data show a rise in infection rates across the country, "but nobody has looked at that association at the national level."

In Ontario, about $30 \%$ of hospitals have stopped screening and isolation for VRE, up from about 20\% in 2015. "There were data out there showing that if you stopped, you wouldn't have a rise in infection rates," Johnstone says. But the evidence came from small studies that didn't follow patients long enough to see a difference. Still, it made it hard for hos- pitals to justify the cost of screening and private rooms for affected patients.

There were also questions about whether VRE infection was that much worse than infection with regular enterococcus, especially because there are new antibiotics that can treat VRE. However, according to a review conducted by Public Health Ontario, patients with VRE infection had worse out- urging that all hospitals and long-term care homes continue screening and using contact precautions for VRE. "We don't want the spread of antibiotic resistant organisms in our hospitals," Johnstone says. "If there are things we can do to prevent that, we should be doing them."

So far, only a handful of hospitals have reinstated screening and isolation for VRE,

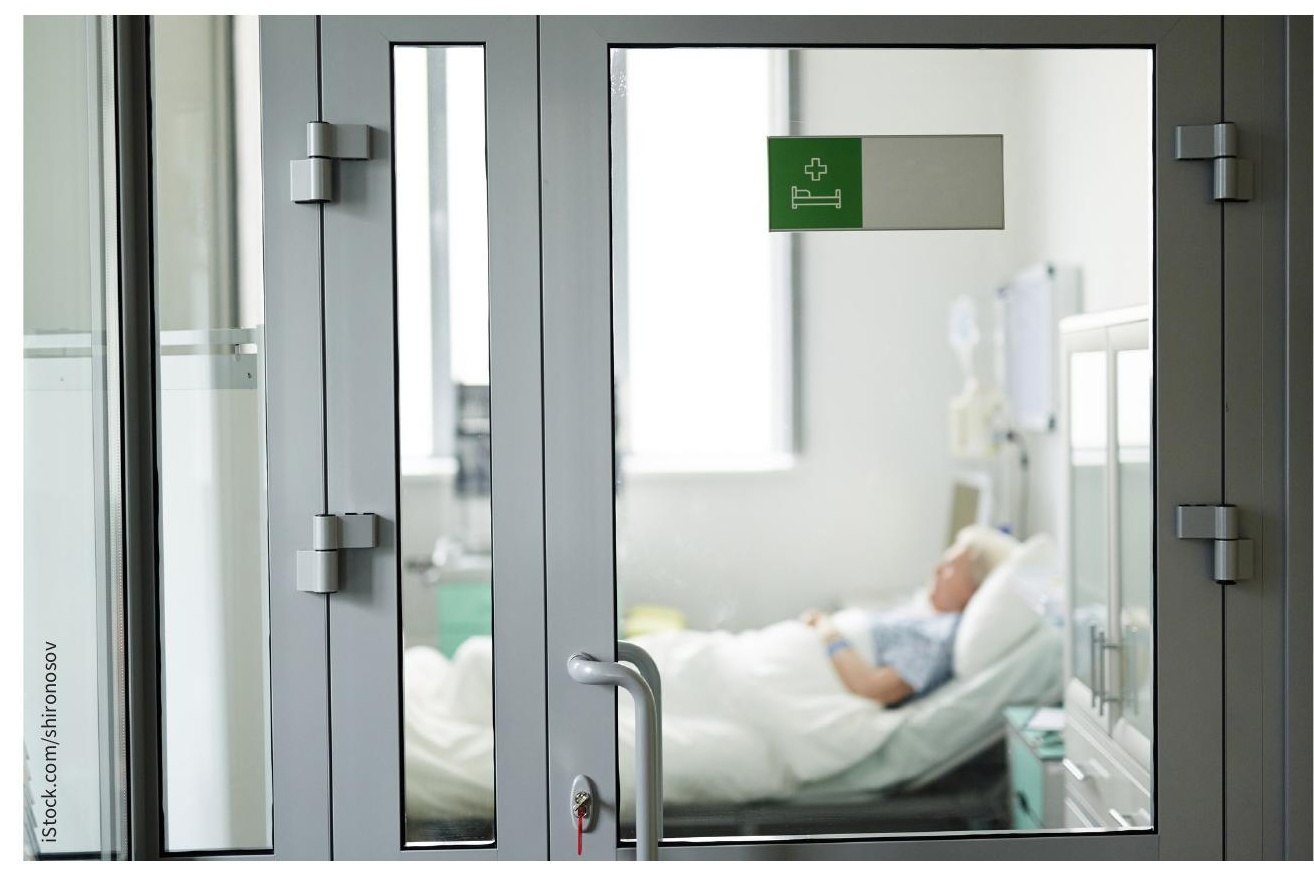

Ontario hospitals that stopped screening for vancomycin-resistant enterococcus and isolating affected patients have seen an "exponential increase" in infection rates.

comes and were more likely to die. Further complicating the picture, a new clone of VRE has emerged that is resistant to lastline antibiotics. It's not possible to tell what role this clone plays in rising infection rates, Johnstone says. "Maybe it spreads more easily and perhaps it's associated with more infections. It's hard to say."

In April, Public Health Ontario issued updated best practice recommendations and some only for their highest-risk patients. "It remains to be seen whether that will work," Johnstone says. It's far easier to stop these programs than to restart them, she notes. "If you do reinstate a screening program in a hospital that has stopped, theoretically, you could have a whole bunch of people who are colonized."

\section{Lauren Vogel, CMAJ}

